\title{
Enriching the International Tourist Experience of Local Malaysian Cuisine and a Guarantee of a Purchase Intention
}

\author{
Mazni Saad', Nadhirah AbdulRahman 2, \\ Muhammad Fikri Umadi ${ }^{3}$ \\ ${ }^{1}$ Kulliyah of Languages and Management, \\ International Islamic University Malaysia, Malaysia \\ 2,3School of Hospitality \& Creative Arts, \\ Management \& Science University, Malaysia \\ maznisaad@iium.edu.my, nadhdo@gmail.com, Fikri.umadi@gmail.com
}

\begin{abstract}
Gastronomy tourism contributes to about one-fifth of the Malaysian economy, indicating that people travel to the country are probably interested in experiencing the taste of the food. This study aims to identify the tourists' experience as well as their purchase intention of local Malaysian food. The findings of 202 international tourists at Bukit Bintang in Kuala Lumpur highlighted both the characteristics of local Malaysian food and environmental factors as significant influences in the tourists' willingness to purchase and to savour local food again. Their potential return visit to the country will benefit the tourism industry and the country's foreign exchange.
\end{abstract}

Keywords: Environmental Factors; Gastronomy Tourism; Malaysian Local Food, Purchase Intention

eISSN 2398-4295 @ 2019. The Authors. Published for AMER ABRA cE-Bs by e-International Publishing House, Ltd., UK. This is an open-access article under the CC BY-NC-ND license (http://creativecommons.org/licenses/by-ncnd/4.0/). Peer-review under responsibility of AMER (Association of Malaysian Environment-Behaviour Researchers), ABRA (Association of Behavioural Researchers on Asians) and cE-Bs (Centre for EnvironmentBehaviour Studies), Faculty of Architecture, Planning \& Surveying, Universiti Teknologi MARA, Malaysia.

DOI: http://dx.doi.org/10.21834/ajbes.v4i16.176 


\subsection{Introduction}

Gastronomy tourism may include food types as well as the properties or characteristics of the food product. There is some quality that is measured by their sensory characteristics (Civille, 1991). Besides the characteristics of food, the surrounding environment plays a vital role in identifying the tourists' experience towards the local food. According to Wansink (2004), there are four important environmental factors relating to food consumption; atmospherics, eating effort, eating with others and also eating distractions based on the individual. The tourists' experience of the local food will then influence their purchase behaviour, which is a willingness to buy a certain product or service (Morwitz, 2012). Consumers stated purchase intentions are one of the primary inputs in studying the impact consumers purchasing behaviours.

Malaysia is well-known not only for its multi-cultural society but also its diverse local delicacies. Its food offerings have become a significant tourist attraction, where every tourist who comes to Malaysia can only claim to have visited the country only after having tried the local food. Malaysia's extensive range of cuisine is the result of its multi-ethnic society which consists of Malay, Chinese, Indian and several other ethnic groups. The tourist is therefore offered a unique and distinctive array of food cooked in many different ways using various types of equipment and serving techniques and accompanied by an assortment of beverages, all of which can be quite fascinating to the tourist (Jalis, 2009). Malaysia's vast culinary gourmet comprises a variety of taste ranging from mild and spicy to sweet and sour, thus making it one of the best places for a gastronomic vacation that introduces the tourist to new flavours of the local food (Yusoff, Zahari, Kutut \& Sharif, 2013). Especially, Kuala Lumpur as the central city of Malaysia, a considerable amount of planning for tourism development to create a friendly destination for all types tourists, in the KL Structure Plan 2020 (Ujang and Muslim, 2014). The Government of Malaysia has planned the city with good facilities, hightech infrastructure services, launching various international tourism programs, and actions.

However, it remains unclear how tourists view and evaluate local Malaysian food and how this evaluation affects their purchase intention. Therefore, research is needed to investigate the positive effect of local Malaysian food and tourist experience as well as their purchase intention. It will focus on the characteristics of local food and environmental factors that could lead to different experiences for the tourist. Hence, the research is essential for the development of Malaysia's tourism industry in general and food tourism in particular. To determine the tourists' level of experience of the local food, this study will be two-fold:

1. To study the effect of the characteristics of local food on the tourist's purchase intention of local food.

2. To study the effect of environmental factors that lead to the tourist's purchase intention of local food. 


\subsection{Literature Review}

\subsection{Consumer Behaviour Theory}

Consumer Behaviour Theory (CBT) underlies this research. The theory relates consumer needs to food and their behaviour towards it. It is also used to study the characteristics of local Malaysian food that the tourists perceive from their experience as contributing to their purchase intention. According to Jeff (2008), CBT is founded by Nicholas Bernoulli, John von Neuman, and Oskar Morgenstern about 300 years ago. It is a study of the processes involved when individuals or groups select, purchase, use or dispose of products, services, ideas or experiences to satisfy needs and desires. In this research, CBT is used to examine the basis of the decision made by the tourists when purchasing local Malaysian food (Jeff, 2008).

\subsection{Characteristics of Local Food}

Food characteristics refer to the external factors of the food itself such as appearance (size, shape, colour, and consistency). It is also based on the texture and flavour that act as the federal grade standard. It falls under food quality element that is acceptable to the consumer and plays a significant role in determining consumer's acceptance based on their personal preference. It marks the level where the food marketer should know the trends and encourage people from another country to try the local food, such as in Malaysia. According to Omar, Karim and Omar (2015), characteristics of the local Malaysian food may especially affect a tourist's purchase intention. Tourists usually get an idea of a country's local food from advertisements, social media and also word of mouth, usually from other tourists.

Tourists enjoy the experience of tasting local food as it serves as a unique attraction and introduction to the local food culture experience. Moginon et al., (2012) who studied indigenous food referred to it as the study of traditional or regional food and emphasised the importance of taste in a later qualitative study among the purveyors. In the study of purveyor, Saad, Abdullah, Adil, and Salleh (2015) found that although the regulated food has met the Malaysian Ministry of Health Dietary Guidelines, lack of taste and variety create persistent rumblings among the consumers.

The cognitive image seems to have a stronger influence than the effective image of preferences for destination food and intention to eat destination food (Seo, Yun \& Kim, 2017). Also, preference for destination food is said to predict an intention to eat destination food. If this be the case, the cognitive image of destination food should, therefore, be identified and strengthened to increase the tourists' intention of eating destination food. Ling et al. (2010) found that when tourists dine in Malaysia, especially at the hawker stalls and night markets, they could see and taste a wide range of local food. Besides experiencing local flavours, tourists also have access to the prices of the food. It can be summarised here that food characteristics can determine a consumer's acceptance of the food which can then lead to a desire to buy the food at some point and perhaps even confirming a perception of the food 
formulated earlier.

\subsection{Environmental Factors}

Environmental factors can be divided into two: eating and food environment. Environmental factors in the context of food according to Edelman, Engell, Bronstei, and Hirsch (1986), refer only to the size of the food portion, where different body weight may result in the intake of different food portions. Wansink (2004) found four important environmental factors affecting food consumption; atmospherics, eating effort, eating with others and also individual eating distractions. Atmospheric factors in food consumption involve lighting, socialising, and eating distraction peculiar to an individual.

Socio-economic status and residential proximity are also environmental factors that affect an individual's food experience, including the availability of fast food restaurant, convenience store and grocery store as their main stop to buy food (Laska et al. (2010). Liese et al. (2014) later said that food shopping behaviour and consumer dietary intake influence their experience of food. They also stated that the availability of food and ease of shopping are also the environmental factors of food consumption. Ma, Blake, Barnes, Bell and Liese (2018) then said that nowadays, the access to different types of food, and food influencer shows a significant result of environmental factors for consumption of food by an individual.

Food safety issues are part of environmental factors which have impacted business performance and competitiveness (Saad, See, Azam, \& Moginon, 2012). Through a simple swab experiment, Saad, See, Abdullah, and Nor (2018) demonstrates that a scientific test can actually contradict perceived knowledge of food hygiene. Food handlers often believe they have sufficient knowledge of food hygiene practices, but often this is not reflected in actual practices, for example, the hygienic cleaning of utensils. Poor practices are observable and often reflect a lack of knowledge of food hygiene.

Jeinie, Nor, Saad, and Sharif (2017) and Saad, See, and Adil, (2018) observed poor practices among culinary students and temporary food handlers and was able to infer their low knowledge level of food hygiene from just their observation. In the same light, the absence of food safety behaviour in food establishments could discourage tourists from purchasing the food because of fear of possible food contamination that would lead to foodborne illnesses. Such negative perceptions of food quality may jeopardise their intention of buying local food. It can also be said that environmental factors of food consumption can be based on the portion size of the food, the surrounding atmosphere, eating effort, eating with others and also eating distractions. Not to mention that food shopping behaviour and socio-economic factors also contribute to environmental factors of food consumption.

\subsection{Purchase Intention}

Customer purchase intention is the customer's willingness to buy a certain product or a particular service. Purchase intention is a dependent variable, which depends on several external and internal factors. A consumer's stated purchase intention is one of the primary inputs that marketing managers use to forecast future sales and to determine how the actions 
they take will impact consumers' purchasing behaviours (Morwitz, 2014). Many factors lead to the customers' purchase intention such as the cultural dimension of individualism, the use of Social Networking Service (SNS), perceived value and the product's perceived quality. According to Moon, Chade, and Tikoo (2008), a customer's purchase intention is affected by the cultural dimension of individualism rather than a price. The authors also stated that consumers increasingly share knowledge, information, and experiences about a product or service through the use of the SNS. The SNS platform establishes and increases consumers' trust and their intention to buy (Hajli, 2015).

Perceived value will give a positive effect on purchase intentions for both potential customers and repeat customers (Setiawan and Achyar, 2013). This is because the more customers feel that they get higher benefits and lesser costs when shopping online, the more they are willing to shop in the online store. Meanwhile, perceived trust effect is greater than the effect of perceived price on purchase intention. Due to the high rate of fraud, customers prefer to buy from an online store that they trust rather than just being offered low prices. Calvo-Porral \& Levy-Mangin (2017) also emphasised that a product's perceived quality will influence the store brand's purchase intention. Repeat customers usually get greater value than potential customers.

\subsection{Characteristics of Local Food and Purchase Intention}

Previous researchers have connected the characteristics of local food to consumer purchase intention. Kim, You, and Rao (2017) stated that several markers of food authenticity such as cooking methods, flavours, and ingredients had been discussed in the current literature. The use of unfamiliar ingredients seems to significantly affect customer's evaluation of the food and purchase intention. Manero et al. (2017) stated in their study that seasoning of vegetables might be instrumental in encouraging consumers who do not often consume vegetables to purchase and ingest them more regularly. This consumer preference for seasoned dishes may be related to consumer perception of additional flavour associated with seasoned food. When several factors of food intake behaviours of Americans were examined, the taste was reported as the most critical deciding factor (Kourounlotis et al., 2016).

As mentioned by Feldmann and Hamm (2015), context serves as the intermediary between characteristics of food and the consumer's behaviour towards it. The study also refers to Zepeda and Deal (2009), which stated that consumers viewed contextual factors like price and availability as very important influences on their actual purchase behaviour. Moreover, one of the articles found showed that food image is significantly and directly related to consumer food satisfaction. The satisfaction of the consumer will be the determinant of the purchase intention (Chi, Chua, Othman and Karim, 2013).

A consumer's perception of food quality without experience can also influence consumer satisfaction and positively affects their purchase intention (Namkung and Jang, 2007). Therefore, the major positive effect between the purchase intention and characteristics of local food is based on how the consumer perceives it. Not only that, the consumer's experience towards the food itself will be the determinant for the intention to purchase, which 
is based on their satisfaction.

\subsection{Environmental Factors and Purchase Intention}

Research has shown that environmental factors are related to consumer purchase intention. The quality of the physical environment is significant to the customer's perceived value and acts as a determinant to consumer satisfaction thus leading to their purchase intention (Ryu, Lee, Gon and Kim, 2012). Also, consumer purchase intention is significant to the customer's involvement in the restaurant, meaning that their experience also leads to purchase intention (Lu and Chi, 2018). The quality of the physical environment will increase consumer satisfaction (Han and Hyun, 2017), and together with the restaurant's background music, it is told that it gives off a better consumer perception and also purchase intention. The positive effect of the restaurant's background music indicates that consumers are prepared to spend money on their main meal (Wilson, 2003).

Although environmental concerns significantly predicted consumer purchase intention for the respondent, there were also results that did not relate to purchase intention in any significant way. Therefore, it can be concluded that most of the time environmental factors, together with experience towards a product to contribute to the consumer's purchase intention. However, there might be some cases where demographic factors surpass the environmental factors of a product and influence their purchase intentions.

The positive effect between Characteristics of Local Malaysian Food, Environmental Factor, and Purchase Intention. Intention to buy encounters many aspects and viewpoints from the consumers but when factors such as characteristics of local food and environmental factors are satisfied, tourists will have a more precise and more positive view of food they wish to buy. Two hypotheses have been developed to unravel these positive effects:

$\mathrm{H} 1$ : Satisfied Characteristics of Local Malaysian Food has a positive effect on Purchase Intention.

H2: Satisfied Environmental Factors has a positive effect on Purchase Intention.

\subsection{Methodology}

The study aims to test the effect of quality local Malaysian food experience on the tourists' experience and their purchase intention. This study employs a combination of a quantitative and cross-sectional research design to test the hypothesis of the research and to examine the effects between the variables (Hsieh \& Shannon, 2005). Hence, a questionnaire survey was chosen with a six-point Likert scale with indicators from " 1 " "strongly agree" to " 6 " strongly disagree was the measurement used. Characteristics of local Malaysian food and environmental factors were adopted from Jalis et al. (2009), while question items for purchase intention were adopted from Chavarria and Phakdeeauksorn (2017), Jalis et al. (2009), and Ling et al. (2010). Adaptations were made to the adopted items to suit the current study.

Subsequently, pre-testing the questionnaire design was conducted with four PhD holders; 
expatriate lecturers from the School of Hospitality and Creative Arts, the Faculty of Health and Life Sciences, and the School of Pharmacy. Feedback from the pre-test resulted in improvements being made to some of the question items in the questionnaire. The following example illustrates: From "Do you like the food?" to "Which type of food do you prefer - Malay, Chinese, or Indian?" The change to a more specific question type was recommended to ensure a clearer understanding of the question as well as a more specific response from the respondents.

The foreign tourists visiting Bukit Bintang in Kuala Lumpur were chosen as the target population because Bukit Bintang is not only well regarded as a remarkable hospitality experience, but is also the trendiest shopping and entertainment district of Kuala Lumpur, which offers everything that international tourists want. However, as no exact number of international tourist population in the area was available a purposive sampling (nonprobability sampling method) to reach out to the target, this study, therefore, used population. As suggested by Salganik and Heckathorn (2004), a sample of 200 to 500 respondents would be an accurate estimation for the study. Data were therefore collected data from 214 survey respondents, computed and finally validated using the IBM-SPSS version 24 software.

\subsection{Results}

\subsection{Sample Profile}

Data collection was conducted within three weeks in April 2018. A total of 214 international tourists participated in the questionnaire survey. Twelve of the questionnaires were invalid as they were completed by tourists who have been in Malaysia for more than a year. However, the survey achieved a total target collection of international tourists at Bukit Bintang as recommended by Salganik and Heckathorn (2004). The first week had a 31.7\% response rate consisting of 64 respondents. The response rate for the second week was $26.7 \%$ consisting of 54 respondents. The third week acquired $41.6 \%$ response rate which consisted of 84 respondents. In total, the survey had a response rate of $100 \%$. Finally, having respondents from various countries helped ensure that the data collected was not bias.

Table 1 shows the difference in respondents' background including gender, age, occupation and country of origin. It also includes their length of stay in Malaysia, the purpose of visiting Malaysia, type of food that they tried and type of food preferred. The profile shows that the respondents were $54 \%$ male and the rest were female (46\%). The profile also detects $53.5 \%$ of respondents were in the range of 21 to 30 years old, and $21.8 \%$ were between 31 and 40 years old. With regards to the international tourists' occupation, $25.7 \%$ were students, $21.8 \%$ were businessmen, $6.9 \%$ were government employees, $20.3 \%$ were private sector employees, and $25.2 \%$ worked in other sectors. As for their country of origin, $48 \%$ of the respondents were from Europe, $11.4 \%$ were from Asia, 9.9\% from America, $8.9 \%$ from Australia, $5.0 \%$ from Africa, while $8.0 \%$ were from the Middle East and other continents. 
Table 1: Respondent's Background

\begin{tabular}{llcc}
\hline Category & & Frequency & Valid \% \\
\hline Gender & Male & 109 & 54.0 \\
& Female & 93 & 46.0 \\
\hline Age & Below 18 years' old & 15 & 7.4 \\
& 21 to 30 years' old & 108 & 53.5 \\
& 31 to 40 years' old & 44 & 21.8 \\
& 41 to 50 years' old & 17 & 8.4 \\
& Above 51 years' old & 18 & 8.9 \\
\hline Occupation & Student & 52 & 25.7 \\
& Businessman & 44 & 21.8 \\
& Government Employee & 14 & 6.9 \\
& Private Sector Employee & 41 & 20.3 \\
& Others & 51 & 25.2 \\
\hline Country of origin & Asia & 23 & 11.4 \\
& Australia & 18 & 8.9 \\
& America & 20 & 9.9 \\
& Africa & 10 & 5.0 \\
& Europe & 97 & 48.0 \\
& Middle East & 17 & 8.4 \\
& Others & 17 & 8.4 \\
\hline
\end{tabular}

Note: $N=202$

Table 2 is this research's descriptive statistics. Based on the 6-point Likert scale, the table of mean scores shows some items with a high average mean ranging from 3.6 to 3.8 where most of the respondents gave positive feedback. The higher mean score is characteristics of local food which is $3.8(\mathrm{SD}=0.54)$, and the lowest mean score is 3.7 for environmental factors $(\mathrm{SD}=.567)$.

Table 2: Descriptive Statistics

\begin{tabular}{lcc}
\hline Variable & Mean & Std. Deviation \\
\hline Characteristics of Local Food & 3.8034 & .54305 \\
Environmental Factors & 3.6535 & .56644 \\
Purchase Intention & 3.7320 & .55575 \\
\hline
\end{tabular}

Note: $N=202$

As for the feedback received on the open-ended question, 152 (75.2\%) were obtained from the surveyed tourists. A total of 63 respondents (41\%) perceive that Malaysia had a variety of local food, with different taste and freshness. Meanwhile, 20 respondents (13\%) commented that the dining area was clean and comfortable. The respondents also agreed that Malaysians had a different style of eating which represented their cultural food. Additionally, nine per cent that commented on the open-ended questions have shown the respondents' willingness to come and purchase local food again. 
Figure 1 shows the percentage of respondents for the responses given according to the variables: characteristics of local food, environmental factor, purchase intention and others. According to Figure $1,41 \%$ of the respondents' comments were related to the characteristics of the local food. This can be clearly seen when some of the comments given were about taste, image, quality and also variety. These statements clearly support the argument that international tourists love and enjoy the flavour of local Malaysian food although some of them thought that it was a bit hot and spicy.

Meanwhile, $13 \%$ of the international tourists' response on environmental factors clearly indicated a good level of cleanliness, a different food culture that they would not find in another country, unique concept of food stalls and the comfortable surrounding area. The responses were also clear about their perception of environmental factors while experiencing local Malaysian food. Most of the respondents commented on the diverse Malaysian culture in the open-ended section, only a few are them actually commented on the cleanliness of the restaurants they visited.

The remaining $9 \%$ gave comments on their purchase intention of local Malaysian food. Some comments included a willingness to buy Malaysian food again shortly, the reasonable price of local food and the attractive technique of preparing food. These answers could hold true because, at the time of the survey, the current exchange rate for Malaysian Ringgit was lower compared to that of other countries. Therefore, international tourists' spending power on food and other related tourism activities was considerably higher.

\section{Feedback from the Open-ended}

\section{Question}

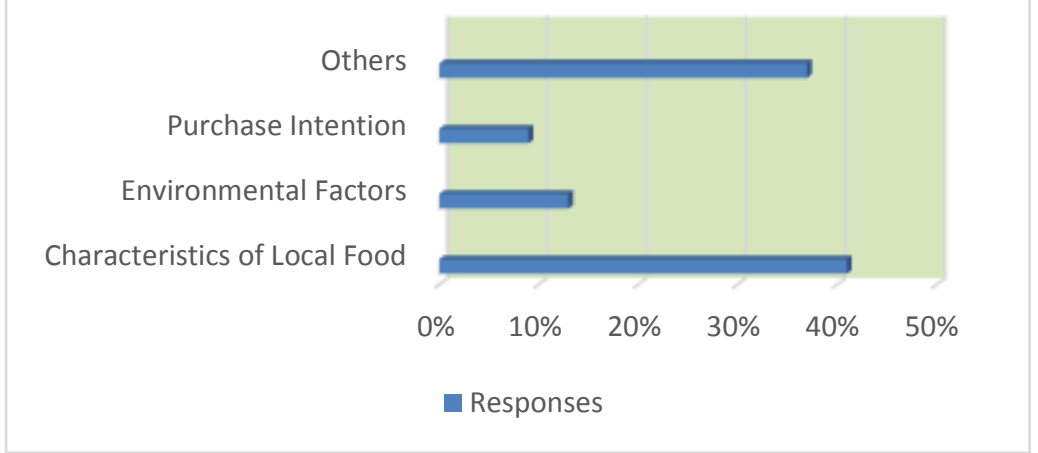

Figure 1: Categories of feedback from the open-ended question

\subsection{Assessment of Cause and Effect Analysis}

As shown in Table 3, the analysis indicates that Characteristic of Local Food ( $B=0.384, t=$ 
5.521, $p<.001)$ had a positive significant effect on Purchase Intention. Similarly, Environmental Factors showed $(B=0.290, t=4.344, p<.001)$, also showing a significant effect on Purchase Intention. Hence, it can be concluded that if the average level of both Characteristics of Local Food and Environmental Factors were high, the average level of Purchase Intention would also be high. The analysis also reveals that the two independent variables were able to explain about $34.8 \%\left(R^{2}\right.$ adjusted $\left.=.341\right)$ of the total variation in Purchase Intention among the tourists.

Table 3. Summary of a regression analysis

\begin{tabular}{llll}
\hline Variable & $\mathrm{B}(\mathrm{SE})$ & Beta \\
\hline (Constant) & $1.213(.247)$ & & 4.914 \\
IV1: Characteristic of Local Food & $.384(.070)$ & .375 & 5.521 \\
IV2: Environmental Factor & $.290(0.067)$ & .295 & 4.344 \\
\hline Note: Dependent Variable = Purchase Intention; Model Fits = F $(2,199)=53.001, p<.001 ; \mathrm{B}=$ Unstandardized \\
$\quad$ Coefficient; beta = Standardized Coefficient; IV = Independent Variable; ${ }^{* \star *} \mathrm{p}<.001$.
\end{tabular}

The ANOVA test was significant $(F(2,199)=53.001, p<.001)$, indicates that the regression model was fit to the data. Also, the normal probability plot (i.e. Figure 2 ) also shows that the model's residual value was normally distributed as the majority of the observed values (small dots) were on the straight line. By looking at the scatter plot of the standardised residual value against the standardized predicted value (i.e. Figure 3), the pattern of the graph was random. According to the graphical method analysis in Figure 3, the residual of thi s model is therefore homoscedasticity. In terms of outliers, there was no outlier since no residual value was outside the boundary of \pm 3.0 standard deviation.

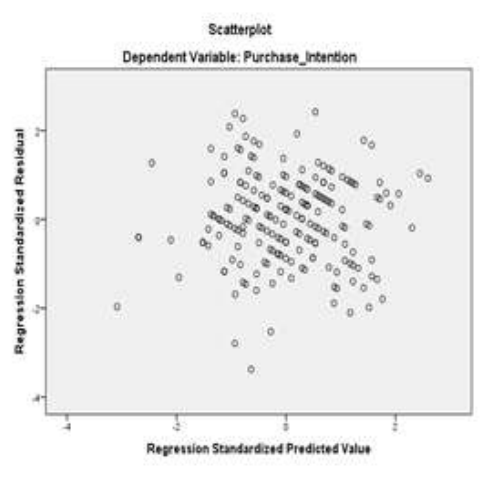

Fig. 2: The Normality Probability Plot of Standardized Standardized Regression

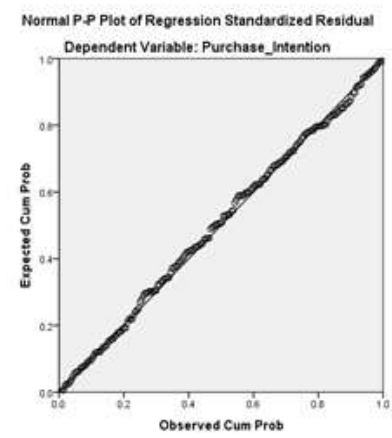

Fig. 3: Illustration Scatter plot of Regression Residual Value 


\subsection{Discussion}

The main objective of this study is to determine the effect of the tourists' experience of the Characteristics of Local Food and Environmental Factors on the Purchase Intention of local food. Based on the responses given in the open-ended question, international tourists mostly perceived local Malaysian food as spicy. However, they thought that it was good in general, as it was very rich in flavour. The positive result of the descriptive statistics is similar to that found Ling et al. (2010). Ling et al. (2010) shows international tourists' strong perception of local food - reasonable food prices, rich flavours, high availability, good services, and variety, although lacking in "clean and safe" places "to eat". The tourist's intention in trying local Malaysian food in this study also aligns with a study by Omar, Karim, and Omar (2015), where characteristics of the local food affected purchase intention, especially for the tourist.

As for the second research question on environmental factors, this study found that the tourists were highly influenced by the different food cultures of Malaysia. It also found that eating hawker style was one of the factors that contributed to the overall international tourists' experience of local Malaysian food. Thus, it is this behaviour that will eventually lead to the purchase and repurchase of food while they are in Malaysia. This study's positive descriptive statistical result is supported by past research done by Liese et al. (2014), which shows that food shopping behaviour and food environment, including the availability of food and ease of direct food shopping influencing an individual's perception of food. Aligns with Ma et al. (2018), this could be related to Malaysia's diverse culture contributing to the wide array of food that is easily available which many international tourists want to try and experience.

The hypothesis testing for this study supported the initial assumptions - this study at first hypothesised that Characteristics of Local Food had a positive effect with Purchase Intention. The hypothesis was supported after the conduct of a regression analysis confirmed that the effect was not only present but was positive and significant. Most of the findings of past research supported the presence of a positive effect between characteristics of local food and purchase intention. The result obtained from a study by Omar, Karim, \& Omar (2015), also aligns with this study, where the significant value was significant at 0.00 levels. The result, therefore, shows that characteristics of local food do influence purchase intention. The second hypothesis linking Environmental Factors to Purchase Intention was also positive and significant. The positive effect was recorded significant. This finding is supported by another research by Lu \& Chi (2018) which found that when a customer is involved in the restaurant and personal experiences the environment, a purchase intention will likely happen.

Table 4: Hypothesis testing

\begin{tabular}{ll}
\hline Hypothesis & Results \\
\hline H1: There is a relationship between & H1 is accepted \\
Characteristics of Local Food and Purchase & Characteristics of Local Food and Purchase Intention \\
Intention. & have a positive relationship and is significant. \\
\hline H1: There is a relationship between & H2 is accepted \\
Environmental Factors and Purchase Intention. & Environmental Factors and Purchase Intention have a \\
\hline
\end{tabular}


Note:

\subsection{Conclusion}

This study indicates that the characteristics of local Malaysian food and environmental factors influence a tourist's purchase intention. The quantitative analysis of the survey points to local Malaysian food characteristics as the biggest contributor to the tourist's purchase intention. It is therefore suggested that the quality of food sold at the local restaurants and stalls be improved in terms of image, taste, freshness, and variety. The local restaurant owner is also advised to revise food prices, apply a reasonable standard for the recipes and enhance the surrounding environment to attract more international tourists into consuming more local Malaysian food.

Theoretically, tourists are attracted to the rich flavour, the spiciness and also the variety of local food, thus for many tourists, this is a reason to travel to Malaysia. Moreover, the cultural diversity and the food bazaars in Malaysia are seen as unique to the country, thus influencing their behaviour towards experiencing it themselves. It can, therefore, be said that CBT is supported by the findings of this study. Practically, many aspects of this study's findings are beneficial. Gastronomy tourism is one tourism product that contributes to the growth of the country's economy. A good evaluation from the international tourists could only be positive to the image of local food and could result in higher tourist arrivals that would help improve the country's economy.

Malaysia's image as a fairly new "food paradise" where people can taste a diversity of delectable food could also benefit from this research's findings. With the rapid growth of the tourism industry, Malaysia has boosted its tourism in the food and beverage industry. The significantly positive results about the international tourists' purchase intention of local Malaysian food are clues that will help restaurant marketers foster a better understanding and knowledge of how to keep the quality, look, uniqueness, and freshness of local Malaysian food. The feedback from international tourists can be used to diversify the choices of local food to offer to the tourists.

With the rapid growth of the tourism industry, Malaysia has boosted its tourism in the food and beverage industry. The significantly positive results about the international tourists' purchase intention of local Malaysian food are clues that will help restaurant marketers foster a better understanding and knowledge of how to keep the quality, look, uniqueness, and freshness of local Malaysian food. The feedback from international tourists can be used to diversify the choices of local food to offer to the tourists. This study should be viewed with certain limitations. The data collection encountered some problems especially in relation to the lack of cooperation especially the Middle Eastern tourists were especially difficult to approach as most of them were not fluent in English, thus resulting in frequent breakdowns in communication between the researcher and the respondent. Therefore, this study has only 
managed to get a majority of western tourists to participate in the survey.

To conclude, this study could be the groundwork for future research that explores how the characteristics of local food and environmental factors affect the total behaviour of international tourists in Malaysia that could lead to their purchase intention. It is suggested that future research explore other factors that could contribute to the tourists' willingness to purchase and taste local Malaysian food. With this purpose in mind, researchers will have to consider expanding the survey to several other tourists' destinations that are related to gastronomy tourism in order to gain new knowledge and perspectives.

This study recommends that improvements be made to how restaurants present local food to international tourists. More effort is needed to keep to the originality of the food; from the taste to the ingredients used to preparation as well as a presentation to the tourists. The local restaurant owner is also advised to provide kueh (local snacks) as a dessert or light food as a way to introduce more local food at night selling. Selling nasi campur (scoop of white rice accompanied by various small portions of side dishes like vegetables, meats, eggs, etc.). For instance, should be continued at night, to balance other types of restaurants like the mamak style (various food often sold by Tamil Muslims), tom yam (spicy soup originated from Thailand), nasi Arab (traditional dish from Middle East countries that contains of rice, meat, and spices), and western food It is also thought that the menu should be customer friendly and not offer too many different cuisines that would confuse the novel diner.

\section{Acknowledgement}

The authors gratefully acknowledge the funding of this article through the 7th Asian Conference on Environment-Behaviour Studies National Taiwan University, Taipei, Taiwan, 09-10 April 2016 best paper award in the conference. The authors are also thankful to the Kulliyah of Languages and Management, International Islamic University Malaysia for permission to attend the conference.

\section{References}

Bishop, K., \& Said, I., (2017). Challenges of Participatory Qualitative Research in a Malaysian and Australian Hospital. Asian Journal of Environment-Behaviour Studies, 2(4), 1-11.

Calvo-Porral, C., \& Lévy-Mangin, J. P. (2017). Store brands' purchase intention: Examining the role of perceived quality. European Research on Management and Business Economics, 23(2), 90-95.

Chavarria, L. C. T., \& Phakdee-auksorn, P. (2017). Understanding international tourists" attitudes towards street food in Phuket, Thailand. Tourism Management Perspectives, 21, 66-73.

Chi, C. G. Q., Chua, B. L., Othman, M., \& Karim, S. A. (2013). Investigating the structural relationships between food image, food satisfaction, culinary quality, and behavioural intentions: The case of Malaysia. International Journal of Hospitality \& Tourism Administration, 14(2), 99-120. 
Civille, G. V. (1991). Food quality: Consumer acceptance and sensory attributes. Journal of Food Quality, 14(1), 18.

Feldmann, C., \& Hamm, U. (2015). Consumers' perceptions and preferences for local food: A review. Food Quality and Preference, 40, 152-164.

Edelman, B., Engell, D., Bronstein, P., \& Hirsch, E. (1986). Environmental effects on the intake of overweight and normal-weight men. Appetite, 7(1), 71-83.

Hajli, N. (2015). Social commerce constructs and consumer's intention to buy. International Journal of Information Management, 35(2), 183-191.

Han, H., \& Hyun, S. S. (2017). Impact of hotel-restaurant image and quality of physical-environment, service, and food on satisfaction and intention. International Journal of Hospitality Management, 63, 82-92.

Jalis, M. H., Zahari, M. S., Zulkifly, M. I., \& Othman, Z. (2009). Malaysian gastronomic tourism products: Assessing the level of their acceptance among the western tourists. South Asian Journal of Tourism and Heritage, 2(1), 31-44.

Jeinie, M.H., Nor, N.M., Saad, S., \& Sharif, M.S. (2017). An Ethnography Survey of Culinary Students' Behaviours in the Implementation of Food Safety and Hygiene Practices. Pertanika Journal Science \& Technology (JST), Vol. 25 (S) August 2017

Kim, J. H., Youn, H., \& Rao, Y. (2017). Customer responses to food-related attributes in ethnic restaurants International Journal of Hospitality Management, 61, 129-139.

Kourouniotis, S., Keast, R. S. J., Riddell, L. J., Lacy, K., Thorpe, M. G., \& Cicerale, S. (2016). The importance of taste on dietary choice, behaviour and intake in a group of young adults. Appetite, 103, 1-7.

Laska, M.N., Hearst, M.O., Forsyth, A., Pasch, K.E., Lytie, L. (2010). Neighborhood food environments: are they associated with adolescent dietary intake, food purchases and weight status? Public Health Nutr. 13(11), 1757-63.

Liese, A. D., Bell, B. A., Barnes, T. L., Colabianchi, N., Hibbert, J. D., Blake, C. E., \& Freedman, D. A. (2014). Environmental influences on fruit and vegetable intake: results from a path analytic model. Public health nutrition, 17(11), 2595-2604.

Ling, L. Q., Karim, M. S. A., Othman, M., Adzahan, N. M., \& Ramachandran, S. (2010). Relationships between Malaysian food image, tourist satisfaction, and behavioural intention. World Applied Sciences Journal, 10 (Tourism \& Hospitality), 164-171.

Lu, L., \& Chi, C. G. Q. (2018). Examining diners' decision-making of local food purchase: The role of menu stimuli and involvement. International Journal of Hospitality Management, 69, 113-123.

Ma, X., Blake, C. E., Barnes, T. L., Bell, B. A., \& Liese, A. D. (2018). What does a person's eating identity add to environmental influences on fruit and vegetable intake? Appetite, 120, 130-135.

Manero, J., Phillips, C., Ellison, B., Lee, S. Y., Nickols-Richardson, S. M., \& Chapman-Novakofski, K. M. (2017). Influence of seasoning on vegetable selection, liking and intent to purchase. Appetite, 116, 239-245.

Moginon, D.F., See, T.P., \& Saad, M. (2012). Indigenous food and destination marketing. Indigenous food and destination marketing. In Z. Artinah, M. R. Salleh, H. Rahmat, T. C. Chemah \& A. Rozita (Eds.), Current Issues in 
Hospitality and Tourism: Research and Innovations (pp. 355-358). Concorde Hotel, Kuala Lumpur Malaysia: Taylor \& Francis Group, London, UK (CRC Press/Balkema).

Moon, J., Chadee, D., \& Tikoo, S. (2008). Culture, product type, and price influences on consumer purchase intention to buy personalized products online. Journal of Business Research, 61(1), 31-39.

Morwitz, V. (2014). Consumers' purchase intentions and their behaviour. Foundations and Trends $₫$ in Marketing, 7(3), 181-230.

Namkung, Y., \& Jang, S. (2007). Does food quality really matter in restaurants? It impacts on customer satisfaction and behavioural intentions. Journal of Hospitality \& Tourism Research, 31(3), 387-409.

Omar, S. R., Ab Karim, S., \& Omar, S. N. (2015). Exploring international tourists' attitudes and perceptions: In characterizing Malaysian Heritage Food (MHF) as a tourism attraction in Malaysia. International Journal of Social Science and Humanity, 5(3), 321.

Ryu, K., Lee, H. R., \& Gon Kim, W. (2012). The influence of the quality of the physical environment, food, and service on restaurant image, customer perceived value, customer satisfaction, and behavioural intentions. International Journal of Contemporary Hospitality Management, 24(2), 200-223.

Saad, M., See, TP., Azam, M.A.M., \& Moginon, D.F. (2012). The impact of food safety practices on organizational performance. In Z. Artinah, M. R. Salleh, H. Rahmat, T. C. Chemah \& A. Rozita (Eds.), Current Issues in Hospitality and Tourism: Research and Innovations (pp. 201-204). Concorde Hotel, Kuala Lumpur Malaysia: Taylor \& Francis Group, London, UK (CRC Press/Balkema).

Saad, M., Abdullah, M.F.F., Adil, M.A.M., \& Salleh, M.F. (2015). Cooking up a Storm! Rising above Challenges in Regulated Food Standards. UPM International Journal of Economics and Management (IJEM), 9 (S), 135-154.

Saad, M., See, T.P., Adil, M.A. (2018). Temporary food handlers' compliance with effective food-hygiene practices. Asian Journal of Behavioural Studies. Vol. 3. No. 10 (2018).

Saad, M., See, T.P., Abdullah, M.F.F., Nor, N.M. (2018). Enhancing Regular Monitoring of Food-Contact Surface Hygiene with Rapid Microbial Kits, Asian Journal of Behavioural Studies. Vol. 3. No. 11 (2018)

Salganik, M. J., \& Heckathorn, D. D. (2004). Sampling and estimation in hidden populations using respondent-driven sampling. Sociological Methodology, 34(1), 193-240.

Seo, S., Yun, N., \& Kim, O. Y. (2017). Destination food image and intention to eat destination foods: a view from Korea. Current Issues in Tourism, 20(2), 135-156.

Setiawan, R., \& Achyar, A. (2013). Effects of Perceived Trust and Perceived Price on Customers' Intention to Buy in Online Store in Indonesia. ASEAN Marketing Journal.

Ujang, N. \& Muslim, Z. (2014). Walkability and Attachment to Tourism Places in the City of Kuala Lumpur, Malaysia. Athens Journal of Tourism, 53-65.

Wansink, B. (2004). Environmental factors that increase the food intake and consumption volume of unknowing consumers. Annu. Rev. Nutr., 24, 455-479.

Wilson, S. (2003). The effect of music on perceived atmosphere and purchase intentions in a restaurant. Psychology of music, 31(1), 93-112. 
Saad, M., et.al. / Asian Journal of Behavioural Studies (AjBeS), 4(16) May / Aug 2019 (pp.33-48)

Yusoff, N., Zahari, M.S.M., Kutut, M.Z.M. \& Sharif, M.S.M. (2013). Is Malaysian food important to local tour operators? Procedia - Social and Behavioral Sciences, 105, 458-465.

Zepeda, L. \& Deal, D. (2009). Organic and local food consumer behaviour alphabet theory. International Journal of Consumer Studies, 33. 697-705. 